

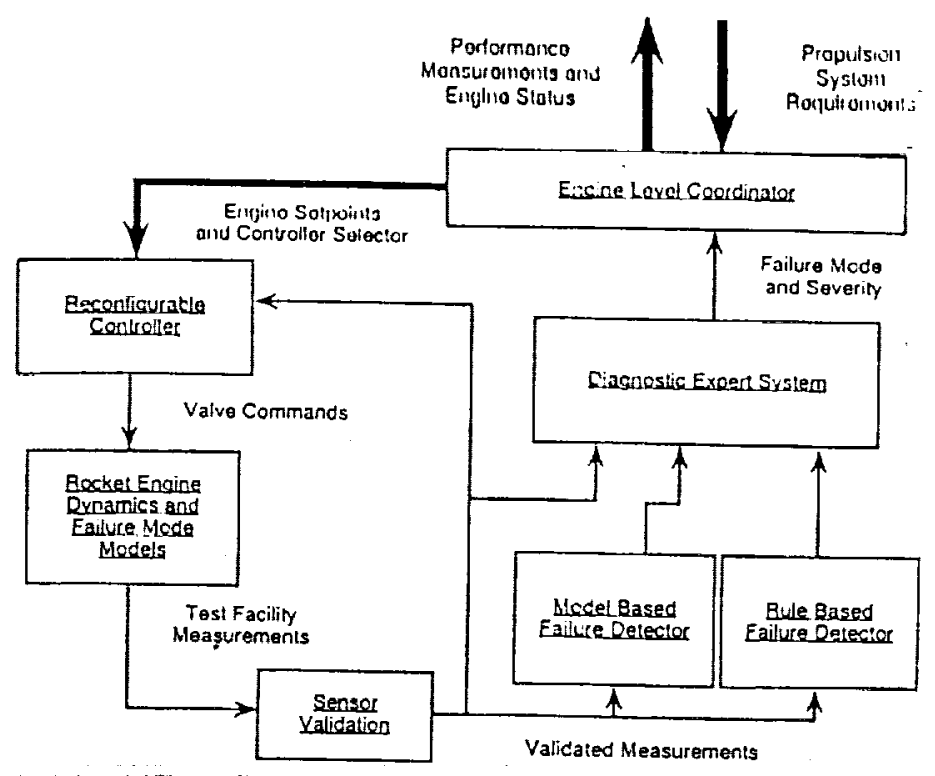

Figure 1 Intelligent Control System Functional Franework

engine level control is responsible for satisfying thrust and mixture ratio demand, avoiding engine conditions having a detrinental impact on hardware durability, and accommodating ellgine component hard/soft faults. As shown in the figure, requirenients flow down in the hierarchy and status information for decision making flows up.

The real-time diagnostic system included in Figure 1 consists of sensor validation, niodel based failure detection, rule based failure detection, and the diagnostic expert system. These functions, described below, are all part of a real-time distributed architecture for diagnostics and are responsible for identifying and isolating any change/degradation in engine valves, sensors or components. The engine level coordinator makes alterations to the control using engine status information generated by the diagnostic system, and propulsion requirements provided by the propulsion level control. The reconfigurable controller takes requests generated by the coordinator, makes the changes gradually thereby minimizing engine transients, and computes the valve positions to achieve the requested behavior from the rocket engine. All operations at the engine level must be performed in real-time, however high sampling requirements are necessary only for the direct control loop which is composed of sensor validation and recontigurable control. Other operations such as decision making in the coordinator may take longer but must still be deterministic to achieve reliable operation.

\section{CONTROLS AND COORDINATION}

Control parameters for a liquid chemical rocket engine traditionally have been pressure and mixture ratio in the main combustion chamber ${ }^{3}$. However, research which explored additional control parameters for closed loop control of a large sciale reusable rocket (Space Shuttle Main Engine) resulted in a number of advanced control moles for the engine based on knowledge gained over years of test experience with that particular cyclet. In decreasing order of importance, the control modes are I) mixture ratio regulation. 2) variable throtling, 3) accommodation of failed actuators t) active control of high pressure turbine temperatures (fuel and

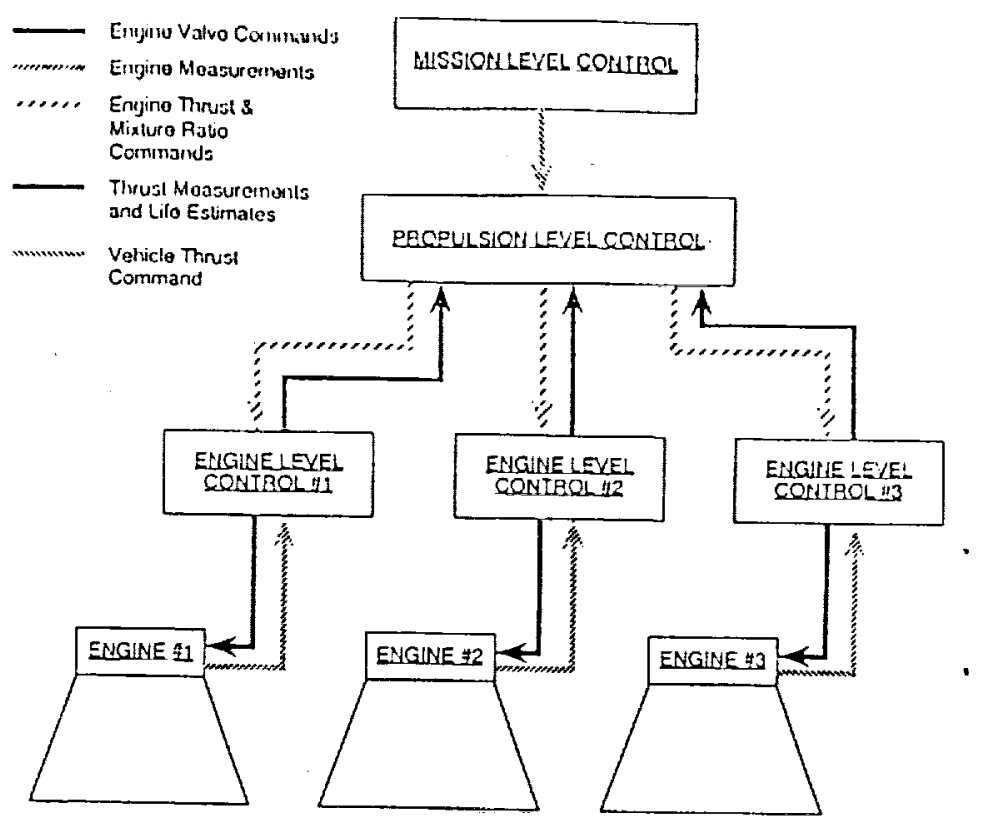

Figure 2 Coordination and Control in the Propulsion Hierarchy

for fault tolerance; and morles 4 and 5 are used for minimizing transients in the engine cycle whose presence have a negative impact on hardware durability and overall engine performance.

Ideally, we would like to achieve independent closed loop control of each of the parameters outlined above to achieve acceptable performance while simultaneously avoiding conditions which shorten hardware life. However, limitations on the availability of valves for regulation of propellant flow on existing SSME hardware constrain the number of parameters for independent control to no more than five. Nemeth ${ }^{4}$ has proposed a number of new valve locations some of which are presently under study by Musgraves. A linear multivariable controls approach is a natural candidate for handling the multidimensional aspects of the problem 5 . However, mode switching is still required given the large number of control parameters if all parameters are to be regulated. For example, high pressure turbine discharge temperatures may be controlled at full power to avoid redlines along with mixture ratio and chamber pressure, while pump inlet pressures may replace the temperatures as controlled variables to achieve rapid throuling without pump cavitation.

Controller reconfiguration is necessary to accommodate those failed valves which play an important role in closed loop operation of the engine. To handle this situntion, a priori control design satisfies thrust and mixture ratio control requirements for the degraded engine with the faulty valve missing from the linear engine design model. Control blending (linear interpolation) is used to bring the new controller on-line and phase out the nominal engine controller. This method will be applied to all identifiable failures requiring control redesign to achieve fault tolerant engine operation.

Coordination occurs at the engine and propulsion levels in the hierarchy of Figure 2. The engine level coordinator niay' change the setpoints of the currently controlled variables to neet performance constraints, avovid detimental operating conditions, change the controlled variables (ie. mode switching). or select an alternate control structure to accommodate a failed or degrated component in the engine system as summarized in Figure 3. Moreover, degradations or 


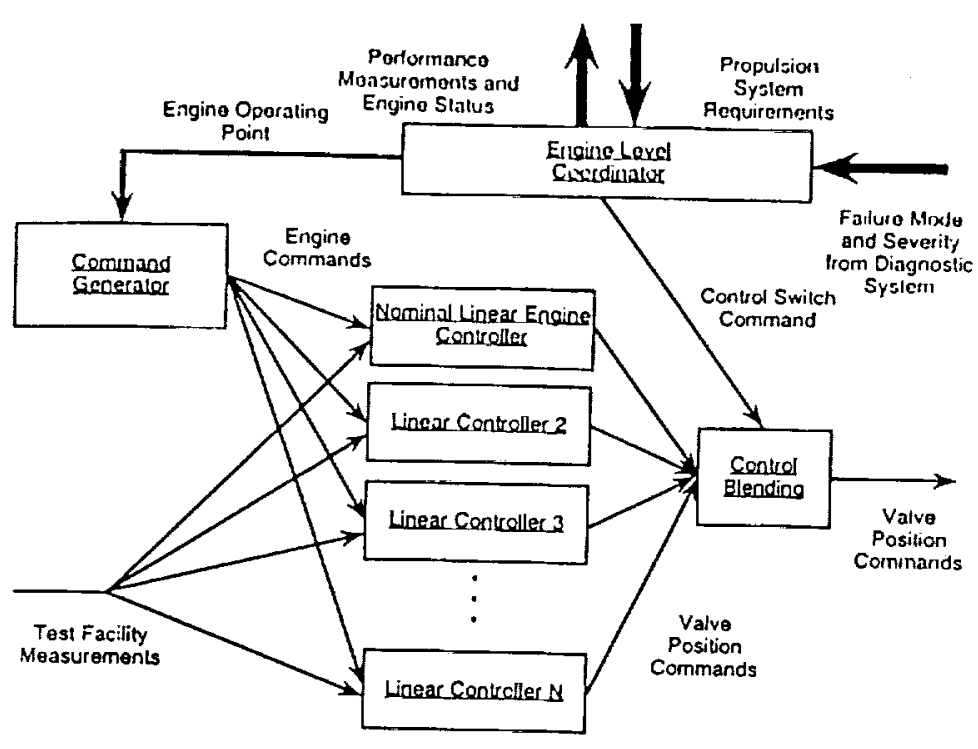

Figure 3 Multivariable Reconfigurable Control

diagnostic system. The engine level coordinator is responsible for neeting thrust and mixture ratio requirements sel by the propulsion level to the extent possible while avoiding an engine shutdown condition. Exact thrust and mixture ratio demands can be met if required by the propulsion level coordinator to avoid loss of mission by limiting the controlled variables to chaniber pressure and mixture ratio. Information about the health of the engine and the necessary performance parameters are supplied to the propulsion coordinator to aid decision making at that level.

The propulsion level coordinator is responsible for managing propellant utilization through mixture ratio commands given to each engine subsystem, setting the thrust levels for each engine to meet mission requirements, and actively controlling propellant tank pressure via liquid hydrogen and liquid oxygen bleed flow in the engine subsystems. The propulsion level coordinator also has the capability to shutdown any engine in the systen or force an engine to operate at levels known by the engine level coordinator to result in an engine shutdown if required for mission success. An example demonstrating propulsion level coordination/control has been demonstrated on a simplified propulsion systen ${ }^{6}$.

\section{DIAGNOSTICS}

A hierarchical, decentralized diagnostic system was proposed for the Real-7ime Dingnostic System component of the ICS franiework 7 . Figure 4 shows the proposed diagnostic system having three "layers" of information processing. These are condition monitoring, fault mode detection, and expert system diagnosis. The condition nonitoring layer is the first level signal processing. Here, important features to be used in the diagnostic system are extracted from the incoming data stream and processed. The processed data are then used by the higher level fault mode detection layer to do a preliminary diagnosis of potential faults at the component level. Becialuse of the closely coupled nature of rocket engine propulsion system components, it is expected that a given fault condition may trigger more than one fault mode detector. For example, a surge in the punip outlet temperature measurement on the low pressure fuel turbopump (LPFTP) may trigger an alarm on the sensor failure detector as well as the LPFTP seal leakage lault mole detector. Expert knowledge is needed to resolve the

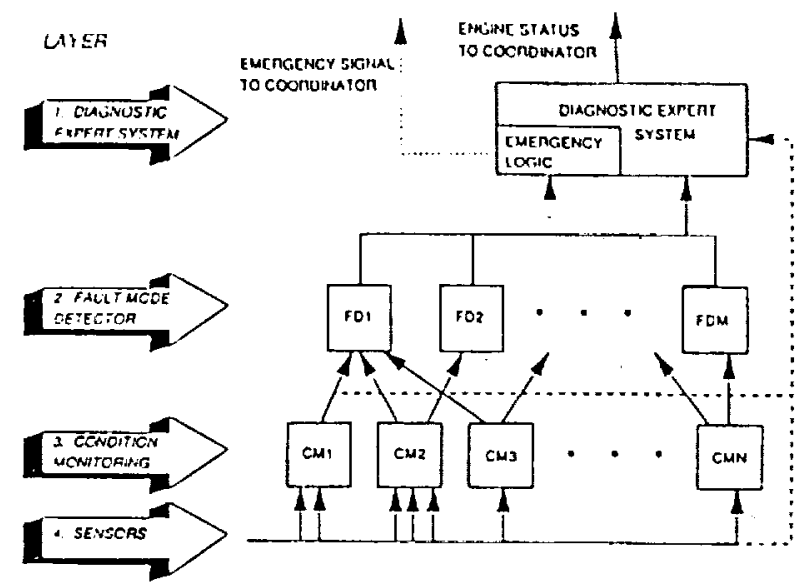

Figure 4 Distributed Diagnostic Architecture

conflicting reports from the various failure mole detectors. This is the function of the diagnostic expert layer. Here, the heuristic nature of this decision process makes it desirable to use an expert system approach.

Implementation of the real-time diagnostic system described above requires a wide spectrum of information processing capability. Generally, in the condition monitoring layer, fast data processing is often needed for feature extraction and signal conditioning. This is usually followed by some detection logic to determine the selected faults on the component level. Three different techniques are used to attack different fault detection problenss 8 . Figure 5 shows the current elements of the distributed diagnostic system. The first technique employed is the neural network application for real-time sensor validation which includes failure detection, isolation and accommodation 9 . The second approach is the model-based fault diagnosis system using on-line parameter identification tecluniques where input data is processed to estimate important parameters for the predefined fault detection logic 10 . Besides these model based diagnostic schemes, there are still many failure modes which need to be diagnosed by heuristic expert knowledge. The heuristic expert knowledge is implemented using a real time expert system tool called G2TM. Finally, the distributed diagnostic system requires another level of intelligence to oversee the fault mode reports generated by component fault detectors. The decision making at this level can be best done using a rule-based expert system.

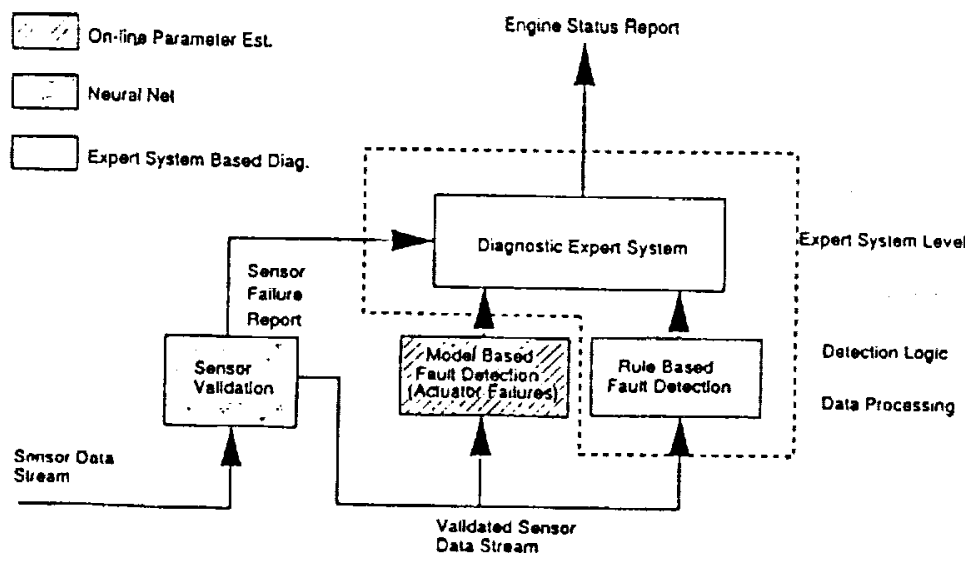

Figure 5 Intelligent Control Diagnustic System

NEURAL NETWORK BASED SENSOR VALIDATION The goals of netural network based sensor validation are 10 i) identify the failed sensor where its output is inconsistent with other measurements, and 2) generate an estimated value for the 
failed sensor. In oder to apply newral netwoiks to sensor validation. a group of analytically redundant sensois is selected. Figure 6 shows the structure of the autoassociative neural nelwork for sensor validation which is trained to generate an on-line estimnte tor each given sensor. In an autoassociative neural network the first halt of the neural network compresses the data into a minimum oides representation and the sccond half of the neural network recovers the encoded information. Because of the information compression and recovery. the ncural network is relatively insensitive to the errors generated by a single sensor fault. By comparing the incoming measurements with corresponding estimates, a sensor failure can be identified if a sensor reading departs from its estimated value while other sensor readings

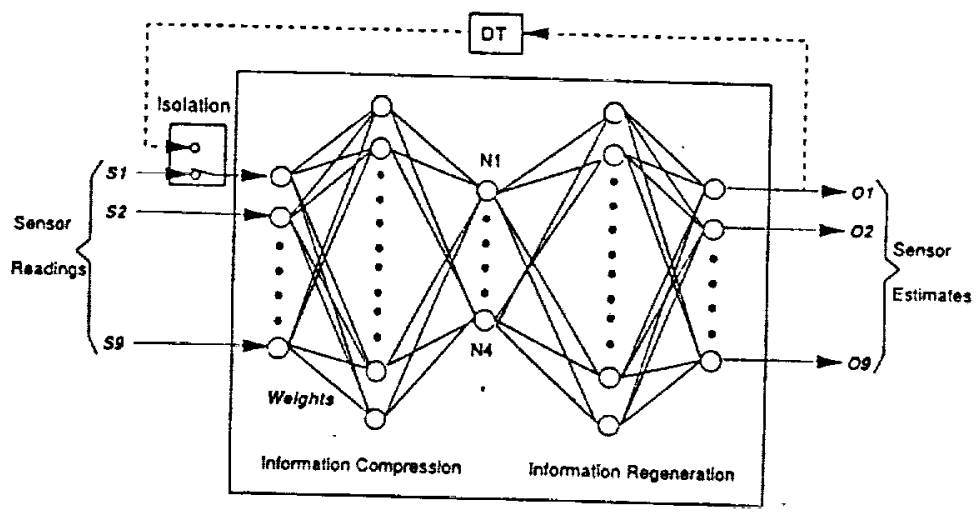

Figure 6 Autoassociative Nenual Network for Sensor Validation

stay close to their estimates. Failed sensor isolation is done by replacing the failed sensor input (to the nettral network estimator) with its estimated value. The neural network then can be used to detect consecutive sensor failures.

MODEL BASED FAULT DETECTION - Model based faull detection uses a molel of nominal operation to detect any abnormal operating behavior that can be classified into a specified structure. The nominal model used here is a piecewise linear model of the Space Shuttle Main Enginell developed from nonlinear simulation data. Figure 7 shows the functional layout of the model based fault detection scheme. Fault modes are classified into actuator faults, sensor failures, and system performance degradations. Each of these three different fault modes is represented by a model with a different structure. Three hypothesis modules (fault model structure) are used to estimate fault parameters of these fault models using an on-line paraneter estimation technicjue. The residuals of each hypothesis module associated with the estimation process are used to select the correct fault hypothesis, and the estimated fault parameters are then used to describe the kind of fault within the selected class. This detection algoritlum has been shown to be very effective for the detection and diagnosis of actuator faults.

RULE BASED FAULT DETECTION - Rule based fault detection is the diagnosis of fault modes using hemistic expent knowledge. Because of the real-time requirement of the Intelligent Control System. the expert system was developed using the real-time expert system shell called G2TM. A rule based diagnostic system for High Pressure Oxidizer Turbopump failure modes has been implentented in G2TAI 12. Also, expert rules are also used to resolve the conflict reports from the sensor failure detection module, the model based fault delection module, and the component fault detection modules.

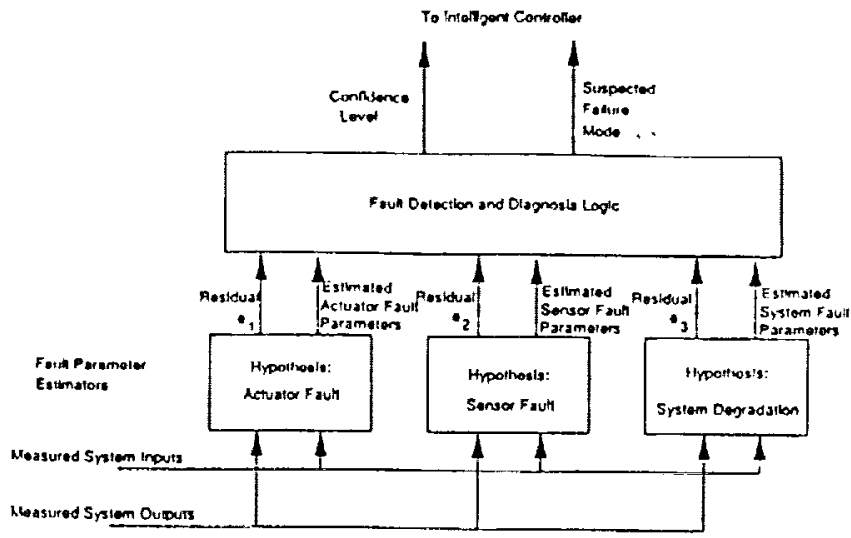

Figure 7 Model-Based Fault Detection and Diagnostic System

\section{SMIULATION TEST BED}

As noted earlier, a key milestone in the development of an ICS for reusable rocket engines is successful integration of real time diagnostics with nulivariable controls. Successful integration can be performed in a simulation environment at a much lower cost without the additional restrictions of limited sensing and other operational constraints associated with a hardware test facility. Moreover, failures or degradations in hardware are expensive to perform and difficult to control making simulation studies a logical first step. Hot fire data can often be used in the development of condition monituring algorithms. However, the ICS has the additional requirement of failure mode accommodation which cannot be studied using historical data. In addition. study of the behavior of the condition monitoring algorithms with closed loop multivariable control is an impostant step in the fine tuning of the diagnostic expert system which is best performed using repeated simulation studies.

Real time implementation of the various technologies under development for the project is an important aspect of the ICS program. For example, inplenentation of expert systems running on conventional hardware remains an open question for sampling rates required for the rocket engine $(50 \mathrm{~ms}-0.5$ sec.) although off-the-shelf products exist for sampling rates over I sec. Emerging technologies such as neural nets are being evaluated for hardware implementation of various tasks including sensor fault detection, isolation and accommodation. Finally, state-of-the-art software tools are being used extensively to develop and generate real time code for implementation of the engine level coordinator, the reconfigurable control and the propulsion level control. In short, a variety of implementation techniques are being considered many of which require further development before application to a rocket engine becomes feasible.

The simulation test bed facility developed at Lewis for proof-of-concept is shown schematically in Figure 8 . The facility consists primarily of four major computers as follows: CIN Unit. Applied Dynamics Intemational ADIO0. Vaxslation 3500. and TI Exploier II LX. The CIN Unit is a special purpuse Control. Interfice and Donitoring conputer developed in-house for performing hardware in-the-loop evaluation of control designs. The ADIOO is a special purpose real time simulation computer complete wilh multichannel analog $1 / 0$ for engine simulation. The Vaxstation 3500 runs a real time rule based expert systein called G2TM developed by GENSYM. Finally, a TI Explorer, a special purpose lisp machine, provides a flexible object oriented enviromment for 


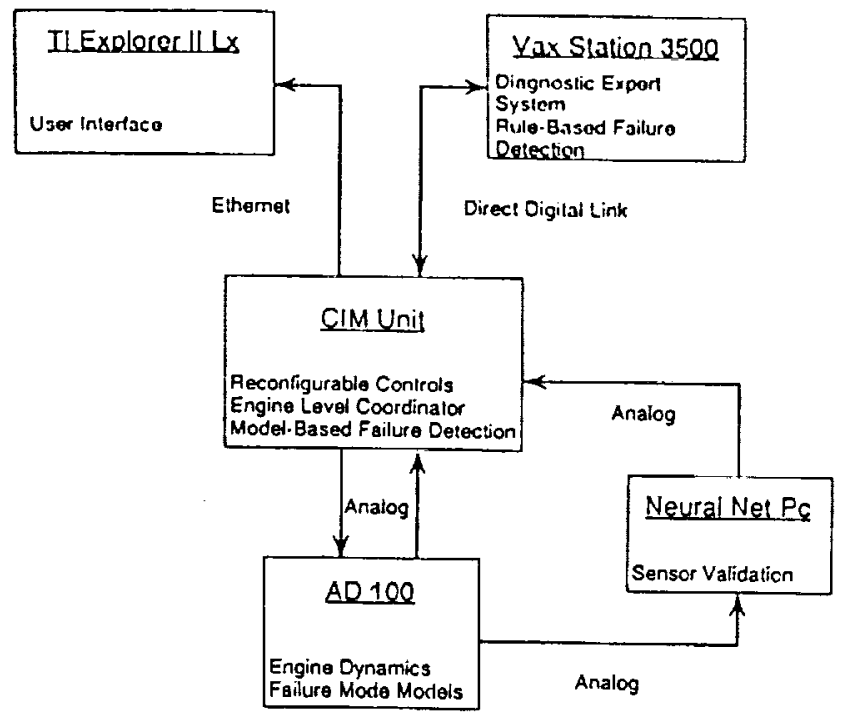

Figure 8 Intelligent Control System Simulation Test Bed

developmenvimplementation of a monitoring interface for the ICS. A personal computer with an ANZATM board implements the neural networks used for evaluating the algorithms and behavior of a "hardware" network in a closed loop system.

Figure 8 also displays the real time potential of the test bed system. The CIM Unit, AD 100, and PC are interconnected with analog links providing real time transfer of data. A direct digital link provides shared memory communication between G2TM and the CIM unit. The user interface does not perform critical functions and does not degrade system performance through the ethernet link. Presently, all hardware is capable of performing its designated tasks in real time with the exception of $\mathrm{G} 2 \mathrm{TM}$ on the Vaxstation which has an update interval of 1 sec. Hence, real time operation of the simulation test bed could be achieved if the speed of the diagnostic expert system could be increased by at least a factor of 10 . Work is ongoing toward meeting this objective for a real time ICS.

\section{CONCLUSIONS}

The current research program at the Lewis Research Center in Intelligent Control Systenis for reusable rocket engines was presented. A functional organization of an intelligent control syste m, called a framework, was developed for a baseline engine. The framework described the integration and coordination of reconfigurable control with real time engine fault diagnostics. The control and coordination functions of this framework were described as well as the real time diagnostics. Important characteristics of the diagnostic system included a decentralized approach to condition monitoring and fault detection. This allows a parallel implementation to achieve real time decision making. Finally, the evaluation of this teclinology is being accomplished on a distributed simulation tesi bed. This test bed not only allows real time evaluation of the ICS functions but it also emulales one possible bread-board implementation.

\section{REFERENCES}

1. Cikanek. H. A.. " Characteristics of Space Shuttle Main Engine Failures." AIAA-87-1939, 23rd Joint Propulsion Conference, San Diego, CA., 29 June - 2 July 1987.

2. Merrill, W. C. and Lorenzo, C. F., "A Reusable Rocket Engine Intelligent Control," AIAA-88-3114.241/ Joint Propulsion Conference, Bosion, MA, July I I-13, 1988.

3. Lorenzo, C.F. and Musgrave. J.L.. "Overview of Rocket Engine Control." Ninth Symposium on Space Nuclear Power Systems, Albutuerque, New Mexico, Jan. 12-16, 1992.

4. Nemeth, E., "Reusable Rocket Engine Intelligent Control System Framework Design," NASA CR187043, April 1991.

5. Musgrave, J. L., "Linear Quadratic Servo Control of a Reusable Rocket Engine," to appear in the Journal of Guidance, Control and Dynamics, Summer 1992.

6. Lorenzo, C. F. and Merrill, W. C., "L,ife Extending Control, A Concept Paper," American Control Conference, Boston, MA, June 26-28, 1991.

7. Guo, T. H. and Merrill, W. C., "A Franework for Real-time Rocket Engine Diagnostics," 1990 Conference for Advanced Earth-to-Orbit Propulsion Technology, Marsball Space Flight Center, AL, May 15-17, 1990.

8. Gun. T. H., "An SSME High Pressure Oxidizer Turbopump Diagnostic Systen Using G2TM Real-Time Expert System," Third Annual Health Monitoring Conference for Space Propulsion System, Cincinnati, Ohio, Nov. 13-14, 1991.

9. Lin, C.S., Wu. I.C., and Guo, T. H., "Neural Networks for Sensor Failure Detection and Data Recovery," Int. Conference on Artificial Neural Networks in Engineering, St. Louis, MO, Nov.10-12, 1991.

10. Guo, T. H., Merrill, W., and Duyar, A., "A Distributed Fault-Detection and Diagnosis System Using On-Line Parameter Estination," IFAC Intemational Symposium on Distributed Intelligeni Systems, Arlington, VA, Aug. 13-15, 1991.

II. Duyar, A., Eldem, V., Merrill, W., and Guo. T., "State Space Representation of the Open Loop Dynamics of the Space Shuttle Main Engine,ASME Jenumal of Dymamic Systems, Measurement, and Control, Vol. 113, No. 4, December 1991.

12. Guo, T.H. "An SSME High Pressure Oxidizer Turbopump Diagnostic System using G2TM Real-Time Expent System." Third Annual Health Monitoring Conference for Space Propulsion Systens, Cincinnati, Ohio, Nov. 13-14, 1991. 
Public reporting burden for this collection of information is estimated to average 1 hour per response, including the time for reviewing instructions, searching existing data sources, gathering and maintaining the data needed, and completing and reviewing the collection of information. Send comments regarding this burden estimate or any other aspect of this collection of information, including suggestions for reducing this burden, to Washington Headquarters Services, Directorate for information Operations and Reports, 1215 Jefferson Davis Highway, Suite 1204, Arlington, VA 22202-4302, and to the Office of Management and Budget, Paperwork Reduction Project (0704-0188), Washington, DC 20503.
1. AGENCY USE ONLY (Leave blank)
2. REPORT DATE
April 1992
3. REPORT TYPE AND DATES COVERED
Technical Memorandum

4. TITLE AND SUBTITLE

Integrated Health Monitoring and Controls for Rocket Engines

\begin{tabular}{l} 
Integrated Health Monitoring and Controls for Rocket Engines \\
\hline 6. AUTHOR(S)
\end{tabular}

W.C. Merrill, J.L. Musgrave, and T.H. Guo

\section{PERFORMING ORGANIZATION NAME(S) AND ADDAESS(ES)}

National Acronautics and Space Administration

Lewis Research Center

Cleveland, Ohio 44135-3191

9. SPONSORING/MONITORING AGENCY NAMES(S) AND ADDRESS(ES)

National Aeronautics and Space Administration

Washington, D.C. 20546-0001
WU $-506-42-72$

5. FUNDING NUMBERS

8. PERFORMING ORGANIZATION REPORT NUMBER

E-7180 AGENCY REF

NASA TM- 105763

11. SUPPLEMENTARY NOTES

Prepared for the SAE Aerospace Atlantic sponsored by the Engineering Society for Advancing Mobility Land, Sea, Air, and Space, Dayton, Ohio, April 7-10, 1992. Responsible person, W.C. Merrill, (216) 433-6328.

12a. DISTRIBUTION/AVAILABILITY STATEMENT

12b. DISTRIBUTION CODE

Unclassified - Unlimited

Subject Category 20

\section{ABSTRACT (Maximum 200 words)}

Current research in intelligent control systems at the Lewis Research Center is described in the context of a functional framework. The framework is applicable to a varicty of reusable space propulsion systems for existing and future launch vehicles. It provides a "road map" for technology development to cnable enhanced engine performance with increased reliability, durability and maintainability. The framework hierarchy consists of a mission coordination level, a propulsion system coordination level, and an engine control level. Each level is described in the context of the Space Shuttle Main Engine. The concept of integrating diagnostics with control is discussed within the context of the functional framework. A distributed real-time simulation test bed is used to realize and evaluate the functionalities in closed loop.

\begin{tabular}{|c|c|c|c|}
\hline \multicolumn{3}{|c|}{$\begin{array}{l}\text { 14. SUBJECT TERMS } \\
\text { Rocket engine; Intelligent control; Integrated diagnostics }\end{array}$} & \begin{tabular}{|c|} 
15. NUMBER OF PAGES \\
6 \\
16. PRICE CODE \\
$\mathrm{AO} 2$ \\
\end{tabular} \\
\hline NSN $7540-01-280-5500$ & & & $\begin{array}{l}\text { idard Form } 298 \text { (Rev. 2-89) } \\
\text { cribed by ANSI Std. Z39-18 } \\
102\end{array}$ \\
\hline
\end{tabular}

